\title{
Reply to the correspondence letter by Alonso-Ojembarrena, Almudena and Oulego-Erroz, Ignacio: How to improve precision and reliability of diaphragm ultrasonographic measurements in newborns
}

\author{
Hesham Abdel-Hady ${ }^{1,2}$ (D) Eslam Bahgat ${ }^{1} \cdot$ Hanan El-Halaby $^{2} \cdot$ Ashraf Abdelrahman $^{3} \cdot$ Nehad Nasef $^{1,2}$ \\ Received: 5 November 2020 / Revised: 5 November 2020 / Accepted: 9 November 2020 / Published online: 13 November 2020 \\ (C) Springer-Verlag GmbH Germany, part of Springer Nature 2020
}

Dear Editor,

We would like to thank Dr. Alonso-Ojembarrena, Almudena and Dr. Oulego-Erroz, Ignacio for their interest in our paper and for their very valuable comments on the methodology. In regard to sonographic assessment; we agree with Dr. Alonso-Ojembarrena and Dr. Oulego-Erroz that appositional view is more accurate in measuring diaphragmatic thickness and diaphragmatic thickening fraction (DTF) compared to the subcostal view. However, the main difference between our study and the previous studies on preterm infants which were cited by Dr. Alonso-Ojembarrena and Dr. Oulego-Erroz in their letter [1-3] is that all previous studies were done on stable infants who were not mechanically ventilated or exposed to positive pressure ventilation compared to our cohort of preterm infants who were all mechanically ventilated. As we previously mentioned in our manuscript, mechanical ventilation triggers ventilator-induced diaphragmatic dysfunction (VIDD) through myofibrillar contractile dysfunction and myofilament protein loss of the diaphragmatic muscles which later results in loss of diaphragmatic thickness, forcegenerating capacity, poor activity, and unloading of the

Communicated by Peter de Winter

Hesham Abdel-Hady

hehady@yahoo.com

1 Neonatal Intensive Care Unit, Mansoura University Children's Hospital, Gomhoria Str., Mansoura 35516, Egypt

2 Department of Pediatrics, Faculty of Medicine, University of Mansoura, Mansoura, Egypt

3 Department of Diagnostic Radiology, Mansoura University Children's Hospital, Mansoura, Egypt diaphragm [4]. In animal models, exposure to positive pressure ventilation was associated with more reduction in the mass of the crural diaphragm, with a decrease of $\sim 20 \%$, compared to the mass of the costal diaphragm which were reduced by $14 \%$ [5]. Since appositional view assesses mainly the costal part of diaphragm, it represents the least exposed part to positive pressure ventilation and very likely that this part does not represent the area of maximum effect of positive pressure ventilation on induction of VIDD. Because we were interested in studying VIDD, as a predictor for failed or successful extubation, we used the B-mode in subcostal view to explore each hemidiaphragm and assess the most moving part of the diaphragm after which M-mode ultrasonography was screened at the most moving point. It would be of interest to further explore this point in future researches by comparing the reliability of different sonographic approaches in terms of assessing VIDD.

In regard to the statistical comments, all our sonographic assessment were done by a single radiologist, and we conducted an intra-observer reproducibility for ten clinically stable preterm infants, age and sex crossmatched with the studied group, who were randomly selected for this purpose. We agree with Dr. AlonsoOjembarrena and Dr. Oulego-Erroz that Bland-Altman plots were inappropriately used in our study and that intraclass correlation coefficient (ICC) was a better method for assessment of intra-observer reliability. However, Pearson's correlation coefficient has been previously used and shown a good correlation for paired parameters used for intra-observer reliability in echocardiography studies [6].

We conducted a repeated measurement for intra-observer reliability using ICC, which is represented in Table 1, and it has shown a significant correlation. 
Table 1 Intraclass correlation coefficient for intra-rater reliability of sonographic diaphragmatic parameters

\begin{tabular}{llll}
\hline Characteristics & $\begin{array}{l}\text { Intraclass } \\
\text { correlation }\end{array}$ & 95\% CI & $p$ value \\
\hline Inspiratory thickness of the right hemidiaphragm (mm) & 0.76 & $0.23-0.93$ & 0.001 \\
Expiratory thickness of the right hemidiaphragm (mm) & 0.89 & $0.65-0.97$ & 0.000 \\
Excursion of the right hemidiaphragm (mm) & 0.65 & $0.09-0.91$ & 0.016 \\
Inspiratory thickness of the left hemidiaphragm (mm) & 0.87 & $0.58-0.96$ & 0.000 \\
Expiratory thickness of the left hemidiaphragm (mm) & 0.79 & $0.17-0.95$ & 0.01 \\
Excursion of the left hemidiaphragm (mm) & 0.75 & $0.30-0.93$ & 0.003 \\
Diaphragm thickening fraction (DTF) of the right hemidiaphragm (\%) & 0.90 & $0.65-0.97$ & 0.000 \\
Diaphragm thickening fraction (DTF) of the left hemidiaphragm (\%) & 0.91 & $0.66-0.96$ & 0.000
\end{tabular}

Data availability My manuscript has no associated data or data will not be deposited.

\section{Compliance with ethical standards}

Conflict of interest The authors declare that they have no conflict of interest.

Ethics approval NA.

Consent to participate NA.

Consent for publication NA.

Code availability NA.

\section{References}

1. Alonso-Ojembarrena A, Ruiz-Gonzalez E, Estepa-Pedregosa L, Armenteros-Lopez AI, Segado-Arenas A, Lubian-Lopez SP (2020)
Reproducibility and reference values of diaphragmatic shortening fraction for term and premature infants. Pediatr Pulmonol 55:19631968

2. Rehan VK, Laiprasert J, Wallach M, Rubin LP, McCool FD (2001) Diaphragm dimensions of the healthy preterm infant. Pediatrics 108: E91

3. Rehan VK, McCool FD (2003) Diaphragm dimensions of the healthy term infant. Acta Paediatr 92:1062-1067

4. Hussain SN, Cornachione AS, Guichon C, Al Khunaizi A, Leite Fde S, Petrof BJ, Mofarrahi M, Moroz N, de Varennes B, Goldberg P, Rassier DE (2016) Prolonged controlled mechanical ventilation in humans triggers myofibrillar contractile dysfunction and myofilament protein loss in the diaphragm. Thorax 71:436-445

5. Gayan-Ramirez G, Decramer M (2002) Effects of mechanical ventilation on diaphragm function and biology. Eur Respir J 20:15791586

6. Bunting KV, Steeds RP, Slater LT, Rogers JK, Gkoutos GV, Kotecha D (2019) A practical guide to assess the reproducibility of echocardiographic measurements. J Am Soc Echocardiogr 32:15051515

Publisher's note Springer Nature remains neutral with regard to jurisdictional claims in published maps and institutional affiliations. 